\title{
Programa de formação em competência em informação: redes de cooperação entre os sujeitos que atuam em espaços de informação, educação e cultura
}

\author{
Meri Nadia Marques Gerlin \\ Universidade Federal do Espírito Santo, Departamento de Biblioteconomia, Vitória, ES, Brasil \\ meri.gerlin@ufes.br \\ Marta Leandro da Matta \\ Universidade Federal do Espírito Santo, Departamento de Biblioteconomia, Vitória, ES, Brasil \\ marta.Im.ci@gmail.com \\ Denise Bacellar Nunes \\ Universidade de Brasília, Biblioteca Central, Brasília, DF, Brasil \\ denisebacellar@unb.br
}

DOI: https://doi.org/10.26512/rici.v12.n2.2019.22032

Recebido/Recibido/Received: 2018-12-14

Aceitado/Aceptado/Accepted: 2019-01-21

Resumo: Diante daquilo que tem sido registrado no Brasil pela Ciência da Informação sobre competência em informação e perante a escassez de programas de formação de competências em Universidades, apresenta-se como objetivo compartilhar um processo de planejamento desse tipo de programa compreendendo bibliotecários, docentes e discentes envolvidos em ações universitárias. Para tanto, realizou-se um levantamento de artigos científicos em bases de dados de periódicos online, considerando a importância da competência em informação e competência leitora em diferentes espaços de (in)formação e educação, como bibliotecas universitárias, escolares e públicas. Como considerações iniciais e não apenas finais, percebeu-se a importância de envolver em programas de formação profissionais que atuam em diferentes espaços de formação da competência em informação, como bibliotecas universitárias, públicas e escolares. A Universidade torna-se, por conseguinte, uma instituição importante em um contexto de formação de redes colaborativas, ao receber a contribuição de profissionais de diversas áreas que possibilitem o planejamento, implementação e execução de programas de competência em informação que também incluam a competência leitora, possibilitando o desenvolvimento de habilidades informacionais e capacidades de leituras mais especificamente, em estudantes e docentes, de modo a fortalecer os processos de ensino, pesquisa e extensão com a comunidade interna e externa.

Palavras-chave: Competência em informação. Competência leitora. Biblioteca Universitária. Sociedade da Informação. 
Programa de formación en competencia en información: redes de cooperación entre los sujetos que actúan en espacios de información, educación y cultura

Resumen: Frente a lo que ha sido registrado por la Ciencia de la Información en Brasil sobre competencia en información y ante la escasez de programas de formación de competencias en Universidades, se presenta como objetivo compartir un proceso de planificación de ese tipo de programa que comprende bibliotecarios, docentes y discentes involucrados en acciones universitarias. Para ello, se realizó un levantamiento de artículos científicos en bases de datos de revistas online, considerando la importancia de las competencias en información y lectora en diferentes espacios de (in) formación y educación, como bibliotecas universitarias, escolares y públicas. Como consideraciones iniciales y no sólo finales, se percibió la importancia de involucrar en programas de formación profesionales que actúan en diferentes espacios de formación de la competencia en información, como bibliotecas universitarias, públicas y escolares. La Universidad se convierte, por consiguiente, en una institución importante en un contexto de formación de redes colaborativas, al recibir la contribución de profesionales de diversas áreas que posibiliten la planificación, implementación y ejecución de programas de competencia en información que también incluyan la competencia lectora, posibilitando el desarrollo de habilidades informativas y capacidades de lecturas más específicamente, en estudiantes y docentes, para fortalecer los procesos de enseñanza, investigación y extensión con la comunidad interna y externa.

Palabras-clave: Competencia en información. Competencia lectora. Biblioteca Universitaria. Sociedad de la Información.

Training program in information literacy: cooperation networks between the subjects that work in spaces of information, education and culture

Abstract: Faced with what has been registered by the Information Science in Brazil about information literacy and the scarcity of skills training programs in universities, it is intended to share a planning process of this type of program comprising librarians, teachers and students involved in university actions. To do so, a survey of scientific articles was carried out in databases of online journals, considering the importance of information literacy and reading competence in different spaces of (in) formation and education, such as university, school and public libraries. As initial and not only final considerations, it was perceived the importance of involving in professional training programs that work in different spaces of information literacy training, such as university, public and school libraries. The University becomes, therefore, an important institution in a context of collaborative network formation, by receiving the contribution of professionals from different areas that enable the planning, implementation and execution of programs of information literacy that also include the reading competence, enabling the development of informational skills and reading skills more specifically in students and teachers, in order to strengthen teaching, research and extension processes with the internal and external community.

Keywords: Information literacy. Reading competence. University Library. Information Society.

\section{Introdução}

O domínio das tecnologias de escrita, informação e comunicação torna-se essencial para a efetivação de processos de busca da informação, leitura com compreensão daquilo que é recuperado e estratégias de aprendizagens significativas, demandando que o sujeito contemporâneo adquira habilidades, conhecimentos e técnicas atitudinais no campo da competência em informação. O desenvolvimento dessa competência requer uma interação social mais efetiva daqueles que atuam em espaços de informação, educação e cultura numa 
sociedade da informação caracterizada pela disponibilização de tecnologias de informação e comunicação.

Tendo em vista que usuários e profissionais da informação necessitam tornarem-se autônomos para aprender ao longo da vida profissional, acadêmica, escolar, dentre outras esferas, a aquisição da competência em informação torna-se indispensável para que possam adquirir conhecimentos e variados níveis de aprendizagens para atuar em áreas igualmente diferenciadas.

De acordo com a Association of College and Research Libraries1 (ACRL) (ASSOCIATION..., 2000), a competência em informacional é necessária às pessoas de todas as áreas, de todos os níveis educacionais e em todos os ambientes de aprendizagem e trabalho, visto que tem por objetivo propiciar a capacitação contínua dos indivíduos, pois, ao buscarem os conteúdos informacionais e ampliarem as suas pesquisas, os indivíduos se tornam mais autônomos e assumem um controle maior sobre o próprio processo de aprendizagem (MATA, 2012, p. 142).

As necessidades informacionais e de aprendizagens devem ser levadas em consideração em uma sociedade em que cada vez mais é necessário aprender a acessar informação e produzir conhecimento. Destaca-se a contribuição da Ciência da Informação no que se refere à proposição de programas de competências incluindo a preocupação com a competência leitora, compreendendo habilidades e técnicas que tornem possível aprendizagens significativas por meio do uso de diferentes modalidades de leituras perpassando a necessidade, o interesse e o prazer (GERLIN, 2017). Repensar a condição humana e técnica é um fator condicionante ao desenvolvimento de competências (habilidades, conhecimentos, técnicas e atitudes) que permitam buscar, recuperar, acessar, trabalhar e produzir informação escrita, visual, oral, dentre outras modalidades compartilhadas em espaços tempos híbridos (presencial e virtual).

Na era da informação, também denominada era digital por conta do fortalecimento de um movimento de conexão da sociedade em rede no final do século $X X$, saberes e práticas de resistências são comumente registradas pelos sujeitos que atuam em instituições escolares, bibliotecas, universidades e em outros espaços em que coexistem as tecnologias da escrita, informação e comunicação. Esse cenário requer uma revolução no campo da pesquisa de forma a envolver bibliotecários, docentes, discentes e demais membros da comunidade interna e externa em planejamentos coletivos que compreendam uma formação (formal e informal) no âmbito do ensino, pesquisa e extensão universitária.

Para promover o acesso ao conhecimento e às experiências leitoras por meio da busca e da recuperação de diferentes informações, as ações das bibliotecas devem privilegiar “[...] as necessidades sociais, atuando também como instituições mediadoras do aprendizado, 
auxiliando no desenvolvimento da competência informacional, visando formar indivíduos críticos, que saibam lidar com o conglomerado informacional” (MATA, 2012, p. 151). No âmbito acadêmico, essa instituição educativa e cultural deve estar atenta às demandas de estudantes, pesquisadores e demais membros de sua comunidade que precisam estar preparados parar lidar com o universo informacional e seus processos, para, assim, conseguirem realizar trabalhos acadêmicos e pesquisas em nível de graduação, iniciação científica, mestrado, doutorado e pós-doutorado.

A universidade pública é o foco do programa de formação em competência em informação que está sendo proposto no contexto das atividades de pesquisas da Universidade Federal do Espírito Santo (UFES) em parceria com a Universidade de Brasília (UnB) e outras instituições parceiras. Para tanto, deverá contemplar uma práxis (teoria e prática) que ocasione em transformação da realidade experienciada por profissionais, discentes e demais membros das comunidades interna e externa. Encontra-se contemplado nesse processo ideais de construção de uma universidade mais solidária e colaborativa no que concerne ao processo de construção de uma sociedade na qual a informação e a educação são direitos que devem ser garantidos a todo e qualquer cidadão (GERLIN; SIMEÃO, 2018).

Diante daquilo que tem sido registrado no Brasil pela Ciência da Informação sobre competências em informação e leitora e, principalmente, que se diferencia das pesquisas comumente realizadas até o momento no contexto do Grupo de Pesquisa Competência em Informação e Processos-Inter-relacionados da UFES, certificado pelo Conselho Nacional de Desenvolvimento Científico e Tecnológico (CNPq), assume-se o propósito de compartilhar o processo de planejamento de um programa de formação de competência em informação compreendendo bibliotecários, docentes e discentes envolvidos em ações de pesquisa e extensão universitárias. Para alcançar esse objetivo, realizou-se um levantamento em artigos científicos em bases de dados de periódicos online, considerando entender a importância das competências em informação e leitora em diferentes espaços de (in)formação, como bibliotecas universitárias, escolares e públicas.

\section{Desenvolvimento}

As discussões teóricas no campo da competência em informação envolvem questões relacionadas com o impacto das novas tecnologias, destacando-se a importância da aquisição de habilidades, conhecimentos, técnicas e atitudes que conduzam aos contextos de busca e recuperação da informação. Entende-se que a competência no campo da informação compreende habilidades informacionais que possibilitem aprendizagens significativas por meio da busca e do uso de diferentes suportes e modalidades de leituras. Perpassando a 
necessidade e o interesse, a competência leitora requer habilidades e técnicas no âmbito da informação nos contextos de acesso, seleção e avaliação em contextos presenciais e virtuais (GERLIN, 2017). Recorrer à leitura tanto como meta de diversão/prazer quanto investigativa, conduz ao ato de compreender os diversos tipos de textos informativos e literários, devendo, portanto, o sujeito adquirir competência para o aprendizado do acesso, avaliação e uso de informações (hiper)textuais em um mundo de diferentes vivências sociais, históricas e humanas.

Essa discussão teórica e prática não pôde deixar de envolver questões relacionadas com o impacto das novas tecnologias na era da informação. Diante desse contexto, a navegação no ciberespaço, fortalecido pela Internet/Web, requer meios para a aquisição de habilidades e competências essenciais para o letramento e alfabetização na contemporaneidade. A alfabetização atualmente requer o conhecimento do alfabeto e instrumentos específicos que possibilitem ler, escrever e narrar com competência na Era digital, enquanto que o letramento perpassa a as práticas de leitura e escrita socialmente constituídas (GERLIN, 2017). O ciberespaço fortalecido pela Web acaba fornecendo formas para a ressignificação das relações sociais, requerendo meios para a aquisição de habilidades e conhecimentos essenciais ao sujeito letrado.

Com um tempo diferenciado em termos de conexão em redes de cooperação e de aquisição das competências em informação e leitora, as tecnologias de escrita, informação e comunicação potencialmente disponibilizam uma gama de recursos importantes para a manutenção das práticas culturais e informacionais preservadas pelos grupos sociais (GERLIN, 2018). Essas competências estão relacionadas com a capacidade de buscar informações efetivas, compreender aquilo que se lê, saber usar equipamentos eletrônicos e ferramentas em processos de seleção. Na medida em que se questiona o que mais tem sido produzido pela Ciência da Informação, um levantamento torna-se necessário de forma a compreender o que é publicado principalmente no campo da competência leitora.

O cenário exposto requer a intensificação de estratégias que procurem dar visibilidade às pesquisas realizadas no Brasil, analisando a dimensão das atividades científicas desenvolvidas sobre os temas elencados em articulação com programas voltados para a competência em informação. Em se tratando do levantamento de experiências sobre competências voltadas para os processos de busca, recuperação e uso efetivo da informação, contempla-se a necessidade da abordagem de ações avaliativas igualmente importantes em um processo de monitoramento e acompanhamento de ações em programas de formação de competências. 
As discussões relacionadas à avaliação da competência informacional devem ser ampliadas, pois se constata que este é um tema muito importante, porém incipiente, que pode auxiliar os bibliotecários e os profissionais envolvidos na realização de programas dessa natureza nas instituições de ensino, bem como diversos pesquisadores (MATA, 2012, p. 152).

No que se refere ao contexto de publicações no campo da Ciência da Informação e áreas afins em que a Biblioteconomia encontra-se inserida, coloca-se em análise pesquisas e experiências que conduzam à criação de programas que compreendam uma formação preocupada com o acesso e a avaliação de informações na era digital, conduzindo, desse modo, profissionais e usuários ao entendimento de diferentes modalidades de "leituras" que possibilitem construções de conhecimentos válidos para um aprendizado ético e colaborativo na sociedade da informação.

\subsection{Desenvolvimento de pesquisa sobre competências em informação e leitora em base de dados online}

Por meio da seleção do conteúdo publicado em artigos científicos em bases de dados de periódicos online, recuperaram-se produções relacionadas com a competência em informação que na íntegra puderam ser acessadas por outras denominações utilizadas para a tradução do termo em inglês information literacy: letramento informacional; alfabetização informacional; competência informacional; dentre outras. Os documentos selecionados proporcionaram colocar em análise processos de busca, leitura e compreensão daquilo que é recuperado e compartilhado em termos de informações. Esses processos acabaram requerendo a aquisição de habilidades, conhecimentos e técnicas atitudinais no campo da competência em informação atravessada pela competência leitora, ao contemplar um trabalho que é realizado no território da universidade, escola, biblioteca e em outros espaços de informação, educação e cultura.

No decorrer do processo foram destacadas cerca de dez pesquisas compreendidas entre os anos de 2011 a 2017, publicadas pelos seguintes pesquisadores: Alcará e Santos (2015, 2013); Almeida (2016); Alves e Suaiden (2016); Azevedo e Gasque (2017); Cavalcante e Sousa (2016); Gasque (2011 e 2016); Gasque e Tescarolo (2010) e Zinn e Gasque (2017). Tendo como base a análise das experiências investigativas registradas em produções científicas, a primeira delas relatou uma ação de pesquisa que envolveu alunos dos Cursos de Arquivologia e Biblioteconomia divididos em dois grupos, tendo como propósito avaliar os efeitos de um programa de intervenção direcionado para a compreensão de leitura desses estudantes, de forma que pudessem aprimorar o desempenho no que se refere às habilidades direcionadas para o entendimento de processos de leitura (ALCARÁ; SANTOS, 2015). 
De forma geral, as sessões da intervenção foram divididas em três partes. Uma parte era destinada à apresentação e reflexão em torno dos conteúdos relacionados à compreensão de leitura e às estratégias de aprendizagem, tais como: a importância da leitura e sua compreensão para as atividades acadêmicas, formação e atuação profissional futura; os processos metacognitivos necessários à compreensão de leitura; as principais dificuldades para a compreensão; os tipos de leitura; a técnica de Cloze e sua utilização para o diagnóstico e desenvolvimento da compreensão de leitura, entre outros. Na outra parte da sessão, eram propostas atividades práticas com o uso de textos preparados com a técnica de Cloze. Vale mencionar que, antes do início de cada atividade eram dadas as orientações necessárias para a execução da tarefa. Por fim, a sessão era encerrada com a correção do exercício prático e uma discussão a respeito dos procedimentos adotados, das dificuldades encontradas e da percepção dos estudantes sobre as tarefas desenvolvidas. Ao final do programa, foi realizada uma avaliação das atividades desenvolvidas no decorrer de todas as sessões (ALCARÁ; SANTOS, 2015, p. 67).

Os resultados não apontaram para uma mudança de nível de compreensão leitora, entretanto as atividades desenvolvidas mostraram-se relevantes no que se refere à conscientização dos estudantes quanto à importância das estratégias de aprendizagens voltadas para a compreensão de leituras e, de maneira geral, para um estudo mais eficiente durante o processo de assimilação. A verificação de que os universitários apresentaram baixo nível de compreensão de leitura, fora acompanhada pela identificação da importância do oferecimento de programas intervencionistas para diagnosticar níveis de compreensão, avaliação e melhorias de condições da competência leitora.

Em seguida apresenta-se o registro de uma outra ação que teve como meta investigar junto com universitários características no que dizem respeito ao uso de estratégias de aprendizagens, compreensão de leitura e orientações motivacionais. O estudo proposto levou em consideração a etapa de escolarização na qual os discentes encontraram-se inseridos (ALCARÁ; SANTOS, 2013). Perante a análise dos dados referentes à avaliação das habilidades dos participantes quanto à compreensão de leitura, uso de estratégias de aprendizagens e orientações motivacionais, registrou-se um resultado inferior ao que se esperava do universitário que deveria apresentar um nível de independência e autonomia em processos de compreensão das leituras.

Considerando-se a etapa de escolarização, o fato de os universitários aqui estudados não apresentarem um nível adequado de compreensão mostra o despreparo desses estudantes ao ingressarem na universidade e, consequentemente, isso pode interferir na sua atuação como futuro profissional e como cidadão (ALCARÁ; SANTOS, 2013, p. 416).

O detalhamento do processo de investigação permitiu apontar "[...] algumas possíveis causas para a falta de competência em leitura, dentre as quais se destacam as deficiências nos níveis de ensino fundamental e médio, o desconhecimento ou uso inadequado 
de estratégias de aprendizagem [...]" (ALCARÁ; SANTOS, 2013, p. 416). Todavia, percebeu-se mesmo assim a existência de motivação e uma tendência para aprender própria de sujeitos que buscam adquirir habilidades e conhecimentos necessários para a aquisição de competências ao longo da vida acadêmica e posteriormente profissional.

Os dados levantados até o momento confirmaram uma urgência em criar oportunidades para potencializar as habilidades cognitivas no contexto do ensino superior e, porque não pensar, que outras instituições fora âmbito da universidade também devam refletir sobre processos colaborativos de desenvolvimento das competências em informação e leitora em parceria com essa instituição. A escola, desse modo, também deve ser colocada em questão para que, assim, se possa alcançar uma autonomia em processos de busca de informação, leitura com compreensão e aprendizagens significativas na contemporaneidade.

A estruturação sistêmica de um conjunto de competências que permitam integração das ações de busca, seleção, acesso, leitura, uso de informação e produção de conhecimento demanda tomada de decisão e problematizações acerca do que tem sido produzido no ambiente escolar. Para colocar em análise a aquisição de competências no âmbito da educação básica é preciso refletir acerca da ausência de formação no campo da informação por parte dos educadores (professores, pedagogos, bibliotecários, etc.), das concepções de ensino tradicionais que em alguns momentos ainda giram em torno das atividades de aprendizagens, da organização de um currículo desprendido do contexto sociocultural da escola e da ausência de programas que possam auxiliar no processo de aquisição de informações necessárias ao sujeito contemporâneo.

Algumas hipóteses nesse sentido são apresentadas por uma pesquisa de campo que procurou entender processos relacionados com a competência em informação na educação escolar, especificamente na educação básica. Dentre elas destaca-se a ausência de infraestrutura adequada de informação, sem com isso deixar de compreender as dificuldades de mudanças da cultura pedagógica e formação inadequada dos professores que precisam estar inseridos em processos de formação (muitas vezes os tornando inaptos a auxiliarem na lida cotidiana com informações novas), assim como, a concepção de ensino e aprendizagem baseada em aulas demasiadamente expositivas e a organização de um currículo inflexível que podem impedir o desenvolvimento de autonomia em processos de aprendizagens (GASQUE; TESCAROLO, 2010).

A despeito das intensas discussões sobre letramento informacional e da manifestação unânime de que ele deve estar incluído em todos os esforços sociais de formação continuada de todos os cidadãos, há ainda o desafio de superar imensas dificuldades para sua implementação na educação básica, o que implica o esforço conjunto de toda a sociedade (GASQUE; TESCAROLO, 2010, p. 53-54). 
Depreende-se que o ato de aprender requer processos de investigações coletivas desde a vivência escolar no ensino fundamental até o ensino médio, tendo para isso o auxílio da biblioteca da instituição como promotora das competências em informação e leitora. Em se tratando da competência no âmbito da informação, ora denominada como letramento informacional, torna-se propício analisar a interligação dos conteúdos de habilidades informacionais aos conteúdos de áreas específicas comumente trabalhados por profissionais de diferentes áreas principalmente que atuam com a docência nesse espaço educativo, de aprendizagens e produção de conhecimentos.

Destaca-se nesse sentido uma outra experiência de pesquisa realizada com arteeducadores no ensino médio tendo como objetivo promover formação básica sobre competência em informação. Dividida em duas etapas, procedeu-se a uma formação no campo da competência em informação e posteriormente a um feedback entre os professores por meio de aplicação de questionário disponibilizado on line. Tendo como umas das metas promover aos docentes competência no âmbito da informação, denominada letramento durante o processo de investigação, bem como possibilitar a identificação de conteúdos de interesse dos sujeitos,

O planejamento, a organização e a realização do curso básico de letramento informacional propiciado aos docentes especialistas, antes da aplicação dos questionários, mostraram-se de suma importância para a aquisição dos conhecimentos sobre o assunto. Os participantes tiveram oportunidade de analisar propostas de interligação dos conteúdos de arte aos conteúdos de letramento informacional (ZINS; GASQUE, 2017), p. 176).

Apesar dos desafios e da necessidade de superação apresentados pelos sujeitos que participaram do curso básico de formação, fora identificada a importância de aplicação de uma proposta no campo da competência em informação mostrando, com isso, a viabilidade de trabalhos voltados para a formação discente numa perspectiva interdisciplinar. A experiência relatada torna visível a necessidade de criação de programas de formação de competências no ambiente escolar, permitindo pensar que o desenvolvimento deles expandem-se para além dos espaços escolares e de informação, presenciais e virtuais, privados e públicos de forma a alcançar uma diversidade de sujeitos na era digital.

O cenário que se apresenta exige uma conexão em redes de colaboração, criando-se dessa forma uma necessidade de cooperação profissional no que se refere ao desenvolvimento de competências em espaços de informação, educação e cultura. A integração dos sujeitos que habitam ambientes presenciais e ciberespaço requer a intensificação da utilização de antigas e novas tecnologias, culminando no oferecimento de produtos e serviços que fornecem acesso às coleções impressas ao mesmo tempo que o 
acesso virtual às bases de dados online. Torna-se também necessário o oferecimento de formações de usuários, nas modalidades presenciais e virtuais, direcionadas para o desenvolvimento das competências necessárias aos processos de busca da informação e leitura com compreensão daquilo que fora recuperado.

O registro da presença das tecnologias de escrita, informação e comunicação de fato atingem espaços como a biblioteca, havendo, com isso, uma exigência de que os bibliotecários contribuam para a formação dos alunos através da mediação de processos informativos que transcendem esse espaço. A participação desse profissional no processo de escolarização acaba sendo uma das metas de uma pesquisa teórica nesse momento enfocada, não apenas no que se refere ao processo educativo mas também voltada para a utilização das fontes de consulta para o acesso à informação, para a aquisição de habilidades e técnicas em processos de uso de informações em áreas diferenciadas (ALMEIDA, 2016).

A pesquisa em questão permite pensar que ao profissional da informação é requerido exercer a função educativa e fornecer o devido apoio em processos de desenvolvimento das competências na biblioteca seja ela universitária ou escolar, tendo em vista que "Não é prática tão diferente se reconhecermos que o bibliotecário, historicamente, sempre teve uma faceta educativa concretizada na ação de promover a leitura, principalmente quando envolvido em ambientes escolares" (ALMEIDA, 2015, p. 3). Na atualidade a biblioteca universitária em específico promove processos de mediação da informação por meio de treinamentos de usuários e, ao contar com as novas tecnologias, oferecendo de forma mais completa um atendimento presencial e virtual (híbrido). A biblioteca de maneira geral deve assumir o compromisso de oferecer programas de formação no âmbito das competências em informação e leitora no formato de eventos e ações como oficinas, encontros monitorados, palestras, rodas de conversas, seminários, dentre outras ações formativas e educativas.

\footnotetext{
A mediação bibliotecária educativa significa não somente auxiliar o usuário a se tornar competente na pesquisa de informações relevantes, mas também, contribuir para o seu processo de desenvolvimento de autonomia de aprendizagem. Para tal propósito, buscar parcerias com os professores é indispensável para uma ação mais pragmática. Essa concepção encontra concordância em Almeida Junior (2004): é a mediação o objeto principal da biblioteconomia, e não a informação (ALMEIDA, 2015, p. 3).
}

O bibliotecário é de fato um mediador da informação, devendo desse modo atuar efetivamente dentro e fora da instituição a qual está ligado profissionalmente e, assim sendo, deve atuar com processos de formação no âmbito da competência em informação. Deverá, para isso, trabalhar conectado em redes de colaboração e aprender a dominar habilidades, técnicas e atitudes no âmbito da informação com o auxílio das tecnologias de informação e comunicação disponibilizadas pela sociedade da informação. 
Os bibliotecários, considerados, tradicionalmente, como mediadores do acesso à informação, estruturaram métodos e técnicas para facilitar a busca e o acesso informacional. No entanto, o lócus informacional, predominantemente até duas décadas atrás, de interação com fontes impressas, passou por uma grande transformação, que se revela contínua, com a massificação das TIC. Dessa forma, conforme preconizado por Zurkowski (1974), é imprescindível à comunidade de usuários das bibliotecas aprender a usar o melhor possível as TIC e as fontes de informação por elas disponibilizadas na realização de suas atividades (ALMEIDA, 2016, p. 15).

A quantidade de trabalhos nacionais relatando práticas sobre os temas abordados ainda é pequena, remetendo a uma demanda de implementação de ações que possam prever uma atuação bibliotecária mais significativa no campo da mediação do acesso à informação (ALMEIDA, 2016). Na direção dos trabalhos que devem ser desenvolvidos na biblioteca escolar e universitária presencialmente e no ciberespaço, destaca-se a necessidade de prever a participação da bibliotecas públicas em processos de desenvolvimento das competências devido essa unidade de informação cada vez mais assumir uma função educativa junto à responsabilidade social e cultural na era digital.

A sociedade da informação apresenta desafios e oportunidades para a biblioteca pública e, com isso, a competência em informação contribui para o desenvolvimento de sujeitos aprendizes autônomos capazes de acessar informações ao utilizá-las ética e criticamente. A apresentação de alternativas para o trabalho da competência no âmbito da informação nesse tipo de unidade de informação permite identificar questões relacionadas com a inclusão digital e com o trabalho colaborativo. A sua função educativa não é algo novo, havendo, portanto, uma reestruturação das funções antigas de forma que se possa atender às demandas novas surgidas na era da informação. Essas novas demandas requisitam o uso das tecnologias de informação e comunicação, bem como a efetivação de um trabalho coletivo que possibilitem competências necessárias para o acesso e uso crítico da informação. Os processos de cooperação deverão envolver sujeitos que atuam em bibliotecas escolares, universitárias e em outras instituições educacionais e culturais (ALVES; SUAIDEN, 2016).

Além dos aspectos que privilegiam a biblioteca pública, a pesquisa apontou para oportunidades de atuação, relacionadas à inclusão digital e ao trabalho colaborativo com outras instituições, por exemplo. A alta penetração das tecnologias da informação e o seu uso massivo para o acesso à informação a tornam um ponto importante a ser considerado quando se trata de letramento informacional. E as bibliotecas públicas, neste sentido, mais do que prover acesso a essas tecnologias, devem fornecer meios para capacitar a comunidade para seu uso crítico e eficaz, contribuindo para a inclusão digital e a democratização do acesso à informação (ALVES; SUAIDEN, 2016, p. 236). 
O processo de competência em informação, denominada ao longo da experiência investigativa como letramento informacional, permite destacar, por meio de pesquisa bibliográfica, a penetração das novas tecnologias no território das bibliotecas públicas. Devendo essa unidade de informação também ser um espaço que ofereça meios de acesso à informação na era digital a um público variado em todos os seguimentos da sociedade (ALVES; SUAIDEN, 2016). Mesmo que os sujeitos que nela atuam profissionalmente e frequentam encontrem dificuldades e desafios para o desempenho da sua missão cultural, deverão privilegiar aspectos educativos e relacionados com a informação na era digital. Ao contar com um trabalho de referência e educação de usuários para atender a um maior número de sujeitos e satisfazer as necessidades de informação, poderá organizar um programa que

[...] deve contemplar também as atividades de formação de usuários tradicionais (visitas guiadas, guias de uso de recursos, assistência personalizada), mas de modo que se integrem aos "novos e mais amplos objetivos de aprendizagem", incorporando as atividades de formação da biblioteca ao ambiente educativo formal e informal da comunidade a que serve (ALVES; SUAIDEN, 2016, p. 219).

No que se refere a implementação de programas de competências, torna-se indispensável prever treinamentos para a utilização de serviços e produtos potencializados pelas tecnologias de informação e comunicação na biblioteca pública. Percebe-se o destaque para a função dessa biblioteca "[...] não apenas na disponibilização de acesso às TIC, mas também no desenvolvimento de competências e habilidades que possibilitem aos usuários ter acesso a esses recursos e utilizá-los para buscar, localizar e usar a informação" (ALVES; SUAIDEN, 2016, p. 231). A necessidade de cooperação é pontuada no que se refere aos programadas de formação de competências, requerendo dessa maneira um trabalho em rede com bibliotecas escolares, universidades, espaços comunitários e outras instituições.

A forma de parceria mais defendida é a estabelecida entre bibliotecas públicas e escolas ou instituições acadêmicas, ou, ainda, as parcerias entre bibliotecas públicas e provedores de informação comunitária, entidades governamentais e empresas privadas e entre bibliotecas públicas e indivíduos da comunidade, como voluntários (ALVES; SUAIDEN, 2016, p. 229).

A exposição acerca da função educativa da biblioteca, da importância da utilização das novas tecnologias e da cooperação entre bibliotecas públicas e outras instituições para o desenvolvimento da competência em informação, direciona à colocação de algumas interfaces entre leitura e competência em informação no contexto digital. Surge, com isso, a citação de uma pesquisa exploratória sobre a produção de objetos de aprendizagens realizada "[...] em uma disciplina de pós-graduação, de uma Faculdade de Ciência da Informação, com estudantes de graduação e pós-graduação (regular e sem vínculo formal)" (GASQUE, 2016, p. 
396). Os resultados mostram que os sujeitos reconhecem objetos de aprendizagem como sendo importantes para potencializar um processo de ensino indissociável da aprendizagem, assim como permitiu entender que se demonstram dispostos e motivados no decorrer da investigação.

Ao reconhecerem a importância dos objetos de aprendizagem para potencializar o processo de ensino aprendizagem, demonstraram disposição e motivação no processo de produção, mas também ressaltaram dificuldades em lidar com os softwares que escolheram para realizar programa. Isso mostra a necessidade de mais investimentos para tornar a interface dos programas mais amigável e intuitiva (GASQUE, 2016, p. 400).

A produção em torno dos objetos de aprendizagens, nesse caso material didático produzido digitalmente que podem ser utilizados no processo ensino-aprendizagem presencial ou virtual, torna-se um recurso potente para a aprendizagem dos alunos. Entretanto, não caberá nesse momento uma exposição mais detalhada tendo em vista que os resultados apontaram para o fato de que os sujeitos demonstraram disposição e motivação para aprender a aprender sem, com isso, desconsiderar a necessidade de melhoria das ferramentas de aprendizagens potencializadas pelas tecnologias de escrita, informação e comunicação.

A proposição de uma reflexão acerca das complexidades apresentadas ao sujeito leitor, bem como a evidenciação de relações de aprendizagens que são estabelecidas com as novas tecnologias, conduz a uma outra ação de pesquisa que coloca em análise a produção de um blog informativo com ênfase em processos de leitura e escrita.

A partir da produção desse ambiente de leituras realizadas por dissentes do Curso de Biblioteconomia para identificar habilidades e técnicas para o uso de ferramentas de comunicação no âmbito digital, a pesquisa relatada trabalha na proposição de uma abordagem metodológica dividida em três momentos: oficina sobre a criação de blogs como espaço de desenvolvimento da escrita; escolha das temáticas dos grupos e produção dos textos no âmbito digital. Com a realização das atividades "[...] ficou claro que é fundamental a empregabilidade de um conjunto de habilidades e competências requeridas para usar diferentes tipos de informação, serviços e produtos, bem como interagir socialmente através dos meios eletrônicos" (CAVALCANTE; SOUSA, 2016, p. 10).

Com intuito de evidenciar a competência em informação e um letramento digital necessário para o uso das novas tecnologias e apropriação da leitura por parte de sujeitos que crescem em uma cultura digital e colaborativa adquirindo novas habilidades, enfoca-se tanto a apropriação das novas tecnologias quanto o exercício efetivo das práticas de escrita e leitura que permeiam o ciberespaço (CAVALCANTE; SOUSA, 2016).

Diante da inserção das Tecnologias Digitais de Informação e de Comunicação (TDIC) em grande parte dos processos desenvolvidos pelos 
sujeitos, torna-se cada vez mais necessário o desenvolvimento de competências técnicas/tecnológicas, cognitivas, culturais e sociais para lidar com a velocidade do acúmulo informacional e a sua imaterialidade característica do mundo digital (CAVALCANTE; SOUSA, 2016, p. 2).

A nova era demanda considerar a autonomia que o ciberespaço proporciona ao sujeito leitor, bem como que a apropriação das tecnologias de informação e comunicação potencializam “[...] leituras hipertextuais, linguagens verbais e não verbais, pesquisas online, criação de blogs, busca e compartilhamento de informações, entre tantas outras possibilidades que levam ao domínio dessas tecnologias" (CAVALCANTE; SOUSA, 2016, p. 2). Para além das práticas pedagógicas e dos movimentos de aprendizagens formais e informais proporcionados na internet/web, as redes de relacionamento proporcionam uma conexão colaborativa e compartilhamentos de leituras, atividades culturais e outras possibilidades.

Ao reforçar a compreensão de que as transformações dos processos comunicacionais e de formação do leitor competente trazem desafios junto ao desenvolvimento de estratégias pedagógicas, considera-se que "O progresso das TIC faz emergir uma cultura informatizada, trazendo diferentes formas de produção, organização, armazenamento, mediação e disseminação da informação" (CAVALCANTE; SOUSA, 2016, p. 6). Por meio das práticas nos campos da informação e leitura educadores e educandos podem lidar com as complexidades trazidas pelo ambiente virtual, cada vez mais fortalecido pelas novas tecnologias e formas diferenciadas de construção de conhecimento que decorrem da produção, do uso, da mediação e da apropriação da informação. A competência em informação voltada para a busca, recuperação e uso da informação no espaço digital implica tanto na apropriação das novas tecnologias, quanto no exercício efetivo das práticas de escrita e de leitura que permeiam a cibercultura.

O letramento digital é considerado como importante para a transição da sociedade da informação para a sociedade da aprendizagem, observando-se algumas questões que são trazidas por uma outra pesquisa teórica acerca do enfraquecimento dos vínculos humanos e da urgência da formação de sujeitos competentes em informação (AZEVEDO; GASQUE, 2017). No contexto da pesquisa abordada, a competência no âmbito da informação é desenvolvida por meio da apropriação de práticas sociais e culturais nas quais os sujeitos contemporâneos estão envolvidos cotidianamente. Essas práticas se dariam por meio do letramento, ou seja, da apropriação social da leitura e da escrita:

Tais práticas são designadas de práticas ou eventos de letramento, porque dão sentido aos usos da leitura e escrita e caracterizam um processo de formação que se prolonga ao longo da vida de cada pessoa e integra as atividades de diferentes grupos humanos [...] (AZEVEDO; GASQUE, 2017, p. 171). 
A aquisição das competências em informação e leitora deve, portanto, ser resultado de uma construção social desde a educação básica, formando sujeitos competentes em informação em ambientes híbridos. Deve considerar uma diversidade de mídias disponíveis dentro e fora do ambiente digital, assim como os efeitos que as tecnologias podem acarretar no cérebro humano e no contexto das relações sociais. "As novas tecnologias de informação e comunicação são instrumentos de práticas de leitura e escrita diferenciadas e desempenham papel importante na organização/reorganização do estado e da condição das pessoas ou grupos, durante as interações [...]" (AZEVEDO; GASQUE, 2017, p. 164). A promoção de uma formação na era da informação contribui com posicionamentos críticos, conscientes e direcionados ao bem comum do cidadão numa sociedade em que se torna necessário aprender a lidar com o universo digital.

\begin{abstract}
Se por um lado o letramento digital possibilita o desenvolvimento da capacidade de lidar com o universo digital, por outro lado o letramento informacional a amplia, ao propiciar o desenvolvimento de competências para buscar e usar criticamente a informação disponível em vários suportes e canais - impressos e eletrônicos - por exemplo, livros, jornais, revistas científicas, audiovisuais, bases de dados, bibliotecas, dentre outros. Ao não considerar somente o ambiente digital, o letramento informacional propõe o equilíbrio entre o uso dos recursos tradicionais e dos digitais no processo de aprendizagem (AZEVEDO; GASQUE, 2017, p. 168).
\end{abstract}

Tendo em vista que os usuários leitores precisam incorporar um enorme fluxo de informações buscados em uma diversidade de suportes e canais de informações, necessitam aprender a produzir conhecimentos ao longo da vida. Destacam-se, por conseguinte, contextos de aprendizagens desde a educação básica que deveriam ultrapassar as relações que são estabelecidas com a graduação no ensino superior.

Por meio de uma pesquisa realizada com estudantes de mestrado e doutorado procura-se repensar aspectos relacionados com o desenvolvimento da competência em informação, visando refletir que a aquisição das habilidades, conhecimentos e técnicas necessárias na pós-graduação são influenciadas pelas experiências estabelecidas com a pesquisa na educação básica, na graduação e pela participação em projetos de iniciação científica (GASQUE, 2011).

Os dados do presente estudo mostram não haver diferenças expressivas entre as atividades de pesquisa na educação básica e na graduação, pois ambas demonstram ser superficiais e pouco orientadas. Entretanto, aquelas proporcionadas pelos programas de iniciação científica confirmam ser significativas por favorecerem uma compreensão melhor dos instrumentos e métodos de trabalho investigativo, principalmente quando as atividades são bem orientadas (GASQUE, 2011, p. 27).

Os pesquisadores em formação necessitam obter competências para o desenvolvimento das capacidades de selecionar e acessar informações em outras etapas de 
sua vida acadêmica e profissional, precisando saber avaliar criticamente as fontes comumente buscadas para a resolução de problemas no espaço presencial e ciberespaço. Diante da constatação de que a busca e o uso eficiente/eficaz da informação requer o desenvolvimento de competências específicas, torna-se necessário adquirir uma visão crítica e fazer um uso ético da informação no âmbito da produção científica e ao longo da vida.

Os resultados evidenciados nesta pesquisa remetem à necessidade de analisar detalhadamente as questões referentes às atividades de pesquisas na pós-graduação [...]. A expectativa é que o estudo contribua para uma reflexão aprofundada sobre a formação dos pesquisadores, especificamente sobre o letramento informacional, dada a relevância desses processos na qualidade do conhecimento produzido e, consequentemente, na comunicação científica (GASQUE, 2011, p. 35).

Compreender a influência da atividade de produção de pesquisa na pós-graduação ligada a um contexto social mais amplo conectado em rede, conduz à necessidade de adquirir habilidades necessárias para a constituição de um pesquisador competente em processos de busca e recuperação de informações, leitura com compreensão daquilo que é recuperado, produção de conhecimentos e compartilhamento de informações. No que se refere a aquisição de um conjunto de atitudes em relação à busca e ao uso da informação, questões relacionadas com a competência em informação são evocadas na medida em que as concepções de trabalhos no âmbito do processo ensino-aprendizagem são colocados em questão.

De maneira geral os artigos foram selecionados de forma que pudessem apresentar um estado da arte do que tem sido produzido no campo das competências em informação e leitora ao envolver uma ligação mais direta principalmente com o campo da educação, permitindo entender o motivo da predileção da maior parte dos pesquisadores pela utilização do termo letramento informacional (termo influenciado pela Educação). Também possibilitaram o início de um mapeamento da dinâmica da atividade de pesquisa e extensionista em bibliotecas universitárias com uma ligação mais diretas com unidades escolares e públicas. Essa conexão em ritmo de colaboração torna-se importante para o planejamento de um programa de competência institucional que possa abarcar os sujeitos que atuam e que se utilizam de uma diversidade de espaços tempos de informação, educação e cibercultura.

\subsection{Proposição do planejamento de um Programa de Competência em Informação direcionado não apenas para a Universidade}

A pesquisa realizada apontou para uma produção investigativa que compreende o planejamento de programas de formação no campo da competência em informação, ao reconhecer a importância da atuação de profissionais e usuários de escolas, espaços 
comunitários, ciberespaço, bibliotecas universitárias, escolares e públicas. Assim sendo, uma rede que possa contemplar a práxis no campo da formação de sujeitos competentes na era da informação poderá ser ampliada ao considerar uma nova cultura social.

Em uma sociedade que requer do sujeito uma formação voltada para a seleção e compreensão da informação buscada em espaços presenciais e virtuais, a competência em informação deve de fato ser adquirida. Os leitores (usuários, profissionais, dentre outros) que atuam em instituições como escolas, bibliotecas e ciberespaço podem utilizar no processo diversas modalidades de leituras, compreendendo desde os tradicionais até os hipertextuais, tornando "[...] possível relacionar a ficção com a realidade, tanto em um formato impresso quanto eletrônico. Desse modo, a disseminação da linguagem textual e imagética carece de arquiteturas preocupadas com a competência leitora" (GERLIN, 2017, p. 14).

$\mathrm{O}$ ato de ler consiste em um processo que contempla uma série de habilidades cognitivas inter-relacionadas com a alfabetização e com o letramento digital, demandando o reconhecimento: dos textos escritos, oralizados e imagéticos; das estratégias de leituras, escrita e oralidade; da obtenção de significados evocados pela memória social e pelo ciberespaço; do conhecimento de mundo do sujeitos; dentre outras (ALCARÁ; SANTOS, 2015).

A leitura requer um conjunto de conhecimentos no âmbito da informação e educação que possam de forma efetiva garantir o sucesso de demandas individuais e coletivas nesse campo, devendo, com isso, a proposição de um programa de competências, antes de mais nada, ocasionar em aprendizagens significativas de forma fazer convergir na aquisição de informações e conhecimentos prévios de mundo que o sujeito possui (GERLIN, 2017). Nessa direção os espaços educativos tornam-se essenciais para a formação de um sujeito sociocultural competente em leitura e em informação.

\footnotetext{
Os espaços educativos se defrontam, atualmente, com o desafio de se reconstituírem hibridamente, mesclando tradição e "inovação", trazendo para o seu contexto uma perspectiva que procura articular as informações e os conhecimentos escolares, proporcionando uma interlocução entre ambos na qual seja possível gestar as competências informacionais [...]. Enfim, sugere-se uma preparação para que os usuários realizem, de forma reflexiva, crítica e cada vez mais autônoma suas atividades de aprendizagem e pesquisa (ALMEIDA, 2015, p. 6).
}

O processo de compreensão daquilo que é recuperado na sociedade da informação, assim como as estratégias de aprendizagens significativas estabelecem uma relação de dependência com a aquisição de habilidades, conhecimentos e técnicas atitudinais no campo da competência em informação. A criação de programas de formação dessa competência deve estar ligada à prática educativa, tornando-se necessário pensar que em processos de planejamento e implementação de um programa seja determinado o uso de instrumentos de 
avaliação próprios aos contextos pedagógico e informacional. "A escolha dos instrumentos depende da especificidade da pesquisa, dos recursos investidos, do programa e/ou da instituição que está conduzindo a avaliação, ou dos objetivos da mesma" (MATA, 2012, p. 148).

Em processos de busca, recuperação e (re)produção de informação a universidade torna-se uma instituição importante dentro de um contexto de formação, ao se comprometer com a capacitação de multiplicadores conectados em redes colaborativas. Deve-se prever, para isso, a contribuição de sujeitos competentes em processos de monitoramento/avaliação de uma formação eficiente e eficaz no campo da informação e possível de uma aplicação efetiva no contexto social, procurando, portanto, interagir com movimentos de formação escolares e comunitários. As atividades avaliativas permitem identificar "[...] se o programa foi bem sucedido, se os objetivos estabelecidos foram alcançados, se houve a aquisição de competências informacionais pelos estudantes, o desempenho dos instrutores e demais membros envolvidos e as implicações para a instituição" (MATA, 2012, p. 142).

Perante o cenário descrito um programa de competência em informação poderá ser dividido em três etapas: (I) Estabelecimento de objetivos e diagnóstico institucional; (II) Viabilização de atividades de capacitação de educadores e (III) Implementação de ações junto aos usuários. Essas etapas devem considerar aspectos referentes à estrutura institucional, a capacitação dos bibliotecários e outros profissionais, a implementação das ações junto aos usuários e a formação de discentes para auxiliar no desenvolvimento das atividades de multiplicação com os demais sujeitos. Tendo como base que o planejamento de um programa de competência em informação deve ser direcionado para a comunidade interna e externa à instituição atendida, apresentam-se fases de desenvolvimento que devem ser pensadas para a execução no âmbito de grupos de pesquisas e extensão universitária.

Os objetivos devem ser propostos numa etapa inicial de acordo com a realidade das unidades de informação que participarão do processo, tendo em vista principalmente as necessidades informacionais e educativas em termos de capacitação dos sujeitos que participarão do processo (Quadro 1). Durante a primeira etapa a proposição da análise diagnóstica institucional realizada para verificar a infraestrutura de todo sistema de bibliotecas participantes é essencialmente necessária, possibilitando identificar os recursos físicos, tecnológicos e humanos que poderão ser empregados no programa. Essa etapa poderá ser realizada a partir de documentos institucionais disponibilizados pela rede de colaboração e, caso necessário, com aplicação de questionário semiestruturado junto aos responsáveis pelas bibliotecas universitárias e colaboradores que atuam em unidades escolares e públicas. 
Quadro 1 - Estabelecimento de possíveis objetivos para o programa de formação em Competência em Informação

\begin{tabular}{|l|l|}
\hline \multicolumn{2}{|c|}{ OBJETIVO GERAL } \\
\hline $\begin{array}{l}\text { Propor a implementação do programa de competências em informação e leitora dentro e fora da } \\
\text { biblioteca universitária }\end{array}$ \\
\hline \multicolumn{2}{|c|}{ OBJETIVOS ESPECíFICOS } \\
\hline $\begin{array}{l}\text { Trabalhar no diagnóstico estrutural da instituição } \\
\text { e da biblioteca universitária }\end{array}$ & $\begin{array}{l}\text { Pensar a capacitação dos bibliotecários de uma rede } \\
\text { colaborativa formada para atuar no programa } \\
\text { composto por bibliotecas pública, escolares e } \\
\text { universitárias }\end{array}$ \\
\hline $\begin{array}{l}\text { Planejar a implementação de ações de } \\
\text { competência em informação junto aos usuários }\end{array}$ & $\begin{array}{l}\text { Prever a formação de multiplicadores (principalmente } \\
\text { graduandos de Biblioteconomia) para auxiliar na } \\
\text { implementação das ações do programa }\end{array}$ \\
\hline
\end{tabular}

Fonte: Dados da pesquisa.

A segunda etapa deverá contar com o desenvolvimento de atividades introdutórias de capacitação profissional voltada para os bibliotecários e outros profissionais da educação, ocorrendo por meio do oferecimento de oficinas temáticas sobre a estruturação de programas de competência em informação inter-relacionados com a competência leitora (Quadro 2).

Essa etapa poderá ser ainda constituída por conteúdos teóricos, práticos e avaliativos, visando que docentes, bibliotecários e demais educadores possam aprimorar suas competências no âmbito da informação e leitura. Cada uma das oficinas será composta por temas e experiências relacionadas com o campo das competências em questão. Detalhes relacionados com a estruturação e recursos necessários para a realização das atividades poderão ser devidamente planejados juntamente com os participantes do processo de formação.

Quadro 2 - Proposição de assuntos e temas direcionados às atividades do programa de competência em informação

\begin{tabular}{|c|c|}
\hline $\begin{array}{l}\text { INTRODUÇÃO AO PROGRAMA DE COMPETÊNCIA } \\
\text { EM INFORMAÇÃO }\end{array}$ & $\begin{array}{lclc}\text { INTRODUÇÃO } & \text { AO } & \text { PROCESSO } & \text { DE } \\
\text { COMPETÊNCIA LEITORA } & & \end{array}$ \\
\hline $\begin{array}{l}\text { * Competência em informação e atuação de } \\
\text { bibliotecários e demais educadores } \\
\text { * Cultura organizacional da biblioteca universitária } \\
\text { * Sistemas de buscas e recuperação da informação } \\
\text { em bibliotecas públicas, escolares e universitárias } \\
\text { * Normalização documentária } \\
\text { * Avaliação das fontes de informação } \\
\text { * Ética no uso da informação }\end{array}$ & $\begin{array}{l}\text { * Diferentes suportes e modalidades de } \\
\text { leituras: textual e imagética } \\
\text { * Habilidades e estratégias para a compreensão } \\
\text { do texto } \\
\text { * Compreensão do hipertexto da página do } \\
\text { livro à tela do computador } \\
\text { * Aprendizado colaborativo e produção de } \\
\text { conhecimento de relevância cultural e social }\end{array}$ \\
\hline \multicolumn{2}{|c|}{$\begin{array}{l}\text { * Experiências tendo a abordagem de temas inter-relacionados com a competência em informação e } \\
\text { leitora }\end{array}$} \\
\hline
\end{tabular}

Fonte: Dados da pesquisa. 
A competência leitora encontra-se inteiramente relacionada com a competência em informação, desse modo, o programa buscará trabalhar com uma combinação de habilidades informacionais, cognitivas e técnicas de forma que possa garantir “[...] a mobilização de conhecimentos que possibilitam aprendizagens significativas, por meio do acesso, uso e avaliação de diferentes modalidades de leituras, perpassando a necessidade, 0 interesse e 0 prazer" (GERLIN, 2017, p. 13). Para tanto, na terceira etapa os bibliotecários e outros profissionais/sujeitos envolvidos realizarão ações no campo dessas competências junto aos usuários de sua instituição. Aa atividades colocadas em prática de modo presencial ou virtual poderão assumir o formato de oficinas, disciplinas, cursos ou ações que possam garantir uma participação dos sujeitos, isto é, aquelas que se adéquem melhor as questões estruturais e aos recursos humanos das instituições que farão parte da rede de formação.

Propor uma estrutura de rede colaborativa que envolva a cooperação requer trocas de experiências voltadas para as áreas das competências em informação e leitora, destacando-se a necessidade de um trabalho cooperativo e colaborativo que deverá envolver processos de comunicação e negociação coletiva diante da viabilidade de formação de profissionais e multiplicadores. Trabalhar com a formação de competências "[...] é muito importante, desse modo, quanto melhor elaborado o planejamento do modelo de rede mais eficiente/eficaz será a comunicação e os benefícios para seus atores sociais" (GERLIN; SIMEÃO, 2018, p. 194).

Será viável que as ações ocorram de modo virtual, conforme a estrutura e apoio tecnológico fornecido, conduzindo a possibilidade de criação de material didático como tutoriais e folders que poderão ser disponibilizados em sites institucionais das bibliotecas e/ou presencialmente. É importante a realização de parcerias com professores, profissionais da área de tecnologia e o apoio administrativo das instituições envolvidas. Perante a proposição de parâmetros para o desenvolvimento de um programa de formação na UFES com o apoio da UnB e de outras universidades que envolvam aspectos relacionados com as competências em informação e leitora, percebe-se a importância da contribuição de profissionais de outras unidades de informação e não apenas da biblioteca universitária.

\section{Considerações finais}

Diante daquilo que tem sido registrado pela Ciência da Informação e áreas afins e que fornece apoio ao processo de planejamento de um programa de competência em informação inter-relacionado com a competência leitora, percebe-se a necessidade de envolver bibliotecários, docentes e discentes comprometidos com pesquisa e extensão universitária, dentre eles se destacam aqueles que gerenciam diferentes contextos de formação em espaços de informação, educação e cultura. Por meio da pesquisa realizada em 
base de dados online percebe-se a importância de trabalhar com uma diversidade de sujeitos que atuam em diferentes espaços de desenvolvimento de competências, como bibliotecas universitárias, públicas e escolares.

Como considerações que não finalizam esse processo investigativo percebe-se a importância de envolver bibliotecários e outros educadores que atuam em diferentes espaços de formação da competência em informação e leitora, dentre eles as bibliotecas universitárias e escolares. A Universidade torna-se, por conseguinte, uma instituição importante em um contexto de formação de redes colaborativas ao receber a contribuição de sujeitos de diversas áreas que possibilitem o planejamento, implementação e execução de programas de competência em informação, possibilitando, com isso, o desenvolvimento de habilidades informacionais na comunidade universitária, mais especificamente, entre estudantes e docentes de modo a fortalecer os processos de ensino, pesquisa e extensão.

\section{Referências}

ALCARÁ, Adriana Rosecler; SANTOS, Acácia Aparecida Angeli dos. Avaliação e desenvolvimento da compreensão de leitura em universitários. Estudos de Psicologia, v. 32, p. 63-73, 2015. Disponível em: <http://www.redalyc.org/html/3953/395351948006/>. Acesso em: 28 fev. 2018.

ALCARÁ, Adriana Rosecler; SANTOS, Acácia Aparecida Angeli dos. Compreensão de leitura, estratégias de aprendizagem e motivação em universitários. Psico, Porto Alegre, v. 44, p. 411420, 2013. Disponível em:

<http://revistaseletronicas.pucrs.br/ojs/index.php/revistapsico/article/view/12258/10416>. Acesso em: 27 mar. 2018.

ALMEIDA, Regina Oliveira de. Mediação e letramento informacional: algumas considerações. Revista Analisando em Ciência da Informação, João Pessoa, v. 4, p. 1-20, 2016. Disponível em: $<$ http://racin.arquivologiauepb.com.br/edicoes/v4_n2/racin_v4_n2_artigo01.pdf>. Acesso em: 19 mar. 2018.

ALVES, Mirian Ferreira; SUAIDEN, Emir José. Bibliotecas públicas e letramento informacional. Em Questão, Porto Alegre, v. 22, p. 214-241, 2016. Disponível em: <http://seer.ufrgs.br/index.php/EmQuestao/article/view/54761/37095>. Acesso em: 16 mar. 2018.

AZEVEDO, Isabel Cristina Michelan de; GASQUE, Kelley Cristine Gonçalves Dias. Contribuições dos letramentos digital e informacional na sociedade contemporânea. Transinformação, Campinas, v. 29, p. 163-173, 2017. Disponível em: $<$ http://www.scielo.br/scielo.php?script=sci_arttext\&pid=S010337862017000200163\&lng=en\&nrm=iso\&tlng=pt>. Acesso em: 16 mar. 2018.

CAVALCANTE, Lidia Eugenia; SOUSA, Laiana Ferreira de. Leitura, letramento digital e competência em informação. Revista Tecnologias na Educação, v. 17, p. 1-12-12, 2016. Disponível em: <http://tecedu.pro.br/wp-content/uploads/2016/09/Art38-ano8-vol17dez2016.pdf>. Acesso em: 16 mar. 2018. 
GASQUE, Kelley Cristine Gonçalves Dias. Objetos de Aprendizagem para o Letramento Informacional. Revista Ibero-Americana de Ciência da Informação, Brasília, v. 9, n. 2, p. 387405, 2016. Disponível em:

$<$ http://periodicos.unb.br/ojs311/index.php/RICl/article/view/2418> Acesso em: 16 mar. 2018.

GASQUE, Kelley Cristine Gonçalves Dias. Pesquisas na pós-graduação: o uso do pensamento reflexivo no letramento informacional. Ciência da Informação, Brasília, v. 40, p. 22-37, 2011. Disponível em: <http://www.scielo.br/scielo.php?script=sci_arttext\&pid=S0100$19652011000100002 \&$ Ing=en\&nrm=iso\&tlng=pt>. Acesso em: 16 mar. 2018.

GASQUE, Kelley Cristine Gonçalves Dias; TESCAROLO, Ricardo. Desafios Educacionais para implementação do letramento informacional na Educação Básica. Educação em Revista, v. 26, p. 41-56, 2010. Disponível em:

<http://www.scielo.br/scielo.php?script=sci_arttext\&pid=S0102-

$46982010000100003 \&$ Ing=en\&nrm=iso\&tlng=pt>. Acesso em: 16 mar. 2018.

GERLIN, Meri Nadia Marques Gerlin. Produção de competência leitora em espaços tempos de informação, educação e cultura. In: SEMINÁRIO HISPANO BRASILEÑO: INVESTIGACIÓN EN INFORMACIÓN, DOCUMENTACIÓN Y SOCIEDAD, 2017, Aracaju, SE. Anais eletrônicos... Aracajú, SE: EDUNIT, 2017. Disponível em:

<https://eventos.set.edu.br/index.php/simeduc/article/view/8628/2891>. Acesso em: 1 mar. 2018.

GERLIN, Meri Nadia Marques Gerlin. Tecendo redes e contando histórias: competências em informação e narrativa na contemporaneidade. Brasília: Universidade de Brasília, FCI UnB, 2018.

GERLIN, Meri Nadia Marques; SIMEÃO, Elmira Luzia Melo Soares. Modelo de rede colaborativa baseado nas competências em informação e narrativa. Brasília: Faculdade de Ciência da Informação, Universidade de Brasília, 2018.

MATA, Marta Leandro da. Aspectos da avaliação da competência informacional em instituições de ensino superior. Em questão, Porto Alegre, v. 18, n.1, p. 141-154, jan./jun. 2012. Disponível em: <https://seer.ufrgs.br/EmQuestao/article/view/22081/19795> Acesso em: 30 ago. 2018.

ZINN, Alexandra César; GASQUE, Kelley Cristine Gonçalves Dias. A construção de um programa de letramento informacional e arte educação. RDBCI: Revista Digital de Biblioteconomia e Ciência da Informação, Campinas, v. 15, n. 1, p. 171-188, jan. 2017. Disponível em: <https://periodicos.sbu.unicamp.br/ojs/index.php/rdbci/article/view/8646067>. Acesso em: 16 mar. 2018. 